\title{
Mendesain Ulang Strategi Milk Run (Studi Kasus Pada Transportasi Logistik Rantai Dingin)
}

\author{
Alexander Batara Marpaung \\ Universitas Bina Nusantara, Jakarta \\ Elia Oey \\ Universitas Bina Nusantara, Jakarta \\ Rianto Nurcahyo \\ Universitas Bina Nusantara, Jakarta \\ Email: Alexander.batara@binus.ac.id
}

\begin{abstract}
Abstrak
Penelitian ini dilakukan untuk mengetahui strategi apa yang harus dilakukan oleh pelaku usaha jasa logistik pihak ketiga yang bergerak dalam cold supply chain industri makanan cepat saji di Indonesia khususnya dalam menghadapi dinamika pertumbuhan ekonomi yang sangat pesat di daerah pinggiran kota, sehingga dapat berkontribusi pada industri rantai makanan di Indonesia, terutama untuk logistik pihak ketiga yang memiliki mitra rantai makanan global. Penelitian dilakukan dari tahun 2017 hingga 2020 dengan melakukan berbagai simulasi distribusi logistik di berbagai kondisi. Penelitian dilakukan dengan menggunakan pendekatan penelitian operasional matematis, di mana uji analisis kuantitatif akan difokuskan pada pendekatan manajemen operasional dengan memperhatikan variabel-variabel sebagai berikut: total jarak tempuh rute; kecepatan lalu lintas; jumlah titik perhentian yang akan dilayani pada rute milk run; lama waktu perjalanan; kapasitas kendaraan terhadap waktu tempuh dan jumlah pelayanan persinggahan; serta batas kapasitas kendaraan yang diperbolehkan pada trayek tertentu. Hasil penelitian menunjukkan bahwa untuk mengelola manajemen transportasi secara optimal, perusahaan harus mempersiapkan perhitungannya dengan baik dalam faktor beban, manajemen jarak tempuh dan waktu, dan pembatasan jalan untuk truk logistik, sehingga dapat melayani mitra rantai makanan mereka dengan baik.
\end{abstract}

Kata Kunci: Desain Ulang Strategi, Milk Run, Transportasi Logistik Rantai Dingin

\section{Pendahuluan}

Milk Run sebagai solusi untuk mengurangi biaya dan waktu pengiriman yang diperkenalkan pada tahun 1995 untuk menemukan potensi wisata sirkuler untuk memanfaatkan truk dan mengurangi biaya logistik (Meusel, 1995) Di mana teori ini kemudian disempurnakan dengan memasukan penggabungan lot pengantaran ke dalam satu lot truk besar untuk memperkecil cost pengantaran maupun memecah ke dalam beberapa parsial lot pengantaran yang menggunakan lot truk kecil untuk mempercepat keseluruhan proses pengantaran (Chopra, 2020). Milk run berasal dari industri susu di AS bahwa pengantar susu mengirimkan seluruh botol susu dan mengumpulkan botol kosong di perjalanan pulang pergi. Sementara kekuatan rantai pasokan berada pada jalur terlemahnya, diperlukan sejumlah strategi untuk memperkuat keseluruhan jalur rantai pasok. Untuk rantai pasokan dingin, pentingnya rantai pasokan yang kuat bahkan lebih kuat, karena waktu dapat menjadi elemen penting untuk produk rantai dingin. Dalam rantai pasokan dingin di mana kualitas produk dapat memburuk seiring waktu, biaya 
dan kepuasan pelanggan dapat diperparah dengan penanganan yang tidak benar di sepanjang rantai pasokan. Oleh karena itu umum bagi perusahaan untuk melakukan outsourcing rantai pasokan dinginnya ke penyedia logistik pihak ketiga untuk mendapatkan skala ekonomis, penanganan material yang lebih baik, keahlian dan teknologi.

Fungsi yang dilakukan oleh pihak ketiga dapat mencakup seluruh proses logistik atau kegiatan yang dipilih dalam proses itu. Menurut Ballou (1999) dan Yan et al (2003) signifikansi aliansi antara perusahaan dan Third Party Logistic (3PL) tergantung pada faktor-faktor berikut yaitu memanfaatkan sumber daya dan kemampuan 3PL untuk memperoleh manfaat skala dari operasi logistik dengan mengurangi biaya logistik dan biaya transaksi perusahaan; Memanfaatkan kemampuan profesional dan ketangkasan 3PL untuk meningkatkan efisiensi operasi keseluruhan dan tingkat layanan pelanggan dalam rantai pasokan; Mengurangi atau menghindari investasi pada perusahaan logistik untuk memberikan lebih banyak sumber daya untuk meningkatkan kompetensi inti perusahaan; Mengembangkan basis kredit melalui aliansi pemasok untuk memupuk hubungan simbiotik dengan meningkatkan keunggulan kompetisi secara keseluruhan dari masing-masing perusahaan.

Layanan rantai dingin di industri logistik Indonesia mencatat pertumbuhan signifikan dalam beberapa tahun terakhir seiring dengan meningkatnya populasi pengguna e-commerce domestik. Terlepas dari dampak pandemi Covid-19 saat ini, industri cold chain di Indonesia rata-rata tumbuh $4 \%$ - $6 \%$ setiap tahun. Pertumbuhan ini didorong oleh meningkatnya pengguna e-commerce yang cenderung memilih berbelanja secara online, termasuk untuk kebutuhan pokok seperti makanan, minuman dan sejenisnya (Hanafi, 2020). Pertumbuhan ekonomi yang baik ini berdampak pada industri rantai makanan, di mana banyak toko makanan cepat saji buka dan memiliki pasar permintaan yang besar. Perusahaan HFL Logistik, sebagai mitra logistik rantai dingin satu merek global di industri makanan cepat saji, menikmati permintaan besar ini. Tetapi masalah muncul karena permintaan di daerah pinggiran kota, muncul lebih cepat dan lebih besar daripada permintaan di kota. Sementara toko makanan mitra klien HFL Logistik di Jakarta belum tumbuh dan berhenti di 38 toko, daerah pinggiran kota mengalami pertumbuhan dari sekitar 10 toko menjadi 62 toko dalam 10 tahun.

$\mathrm{Xu}$ et al (2010) berpendapat bahwa dalam industri makanan, kemunduran muncul terutama pada produk-produk segar, karena umur simpannya yang pendek dan mudah rusak. Karena makanan segar sangat menuntut kontrol suhu yang tepat dalam seluruh proses logistik, setiap kegiatan logistik seperti transportasi, penyimpanan, pemuatan dan pengemasan, menjadi tantangan. Untuk mengendalikan keamanan pangan secara efisien dalam proses rantai dingin, dan untuk meningkatkan pemantauan kualitas dan sistem manajemen proses logistik rantai dingin, maka menjadi perhatian pemerintah dan perusahaan, serta topik penting untuk penelitian. (Ebben, 2005) mempelajari masalah penjadwalan kendaraan dinamis dengan berbagai kendala kapasitas sumber daya dan dengan mengembangkan metode penjadwalan serial khusus dan menganalisis perilaku dinamisnya menggunakan simulasi kejadian diskrit.

Menjalankan milk run di toko-toko rute kecil adalah cara terbaik untuk mencapai pemanfaatan armada, tetapi masalah muncul ketika berlari ke sejumlah besar pengiriman titik yang akan membawa kompleksitas dalam koordinasi dengan tidak hanya kedua belah pihak tetapi juga orang lain yang terlibat dalam milk run ini (Chopra, 2020). Ada beberapa faktor yang perlu dipertimbangkan:

a. Faktor kapasitas beban - Untuk memanfaatkan lebih banyak kapasitas, akan menyebabkan kendaraan transportasi melompat keluar dari rute reguler ke toko lain, rute lalu lintas yang rusak ini dari cara normal dan efisien, sehingga menghasilkan lebih banyak konsumsi bahan bakar. (Hall, 1987)

b. Memuat dan membongkar faktor waktu - Selain waktu untuk rute perjalanan, yang mungkin perlu dipertimbangkan oleh industri logistik adalah waktu ketika melakukan 


\section{Alexander Batara Marpaung, Elia Oey, Rianto Nurcahyo}

bongkar muat barang dari kendaraan. Dalam hal ini akan memakan waktu sekitar 15 hingga 30 menit tergantung pada desain toko, yang menyebabkan kesulitan bagi pengemudi dan timnya untuk menurunkan barang ke toko.

c. Kondisi lalu lintas dan faktor rute - Banyak metode manajemen rute transportasi, sering memiliki keterbatasan ketika datang ke kondisi lalu lintas, yang secara dinamis berubah setiap hari. Searah jarum jam dan rute yang berlawanan dengan arah jarum jam, juga akan membawa perbedaan signifikan dalam waktu, jarak tempuh, dan hasil konsumsi bahan bakar. (Arvidsson, 2013).

d. Faktor pembatasan kapasitas jalan - Banyak jalan di Indonesia, terutama Jakarta dan kota di sekitarnya, memiliki batasan baik dalam berat dan ukuran kendaraan. Tidak semua jalan memungkinkan untuk masuk dengan kargo rantai dingin truk besar yang bisa membawa kargo truk kulkas berkapasitas 20 atau 26 kaki. Ini membuat situasi semakin buruk, dan manajer transportasi harus mengevaluasi semua rute dan strategi armada mereka.

Di bidang rantai pasokan makanan dingin, kecepatan dan kualitas transportasi menjadi perhatian utama karena masalah keamanan pangan. Karena alasan itu, perusahaan sekarang menggunakan teknologi untuk meningkatkan rantai pasokan dingin makanannya, seperti yang dijelaskan oleh Zhang \& Chen (2014) yang mempelajari penggunaan teknologi canggih dari Internet untuk mewujudkan pemantauan waktu nyata perpustakaan dan pelestarian. barang dalam transit, logistik rantai dingin pihak ketiga. Marius \& Lu (2013) mempelajari praktik serupa tetapi lebih canggih dengan menggunakan wadah cerdas dalam rantai pasokan dingin untuk membantu mengendalikan suhu selama pengiriman dan lokasi geografisnya.

\section{Landasan Teori}

Manajemen operasi adalah suatu rangkaian kegiatan yang menciptakan nilai dalam bentuk barang dan jasa dengan mengubah input menjadi output. Kegiatan menciptakan barang dan jasa terjadi di semua organisasi. Di perusahaan manufaktur, aktivitas produksi yang menghasilkan barang biasanya cukup jelas. Di dalamnya, kita bisa melihat penciptaan produk yang nyata. Dalam organisasi yang tidak menciptakan barang atau produk berwujud, fungsi produksi mungkin kurang jelas. Kegiatan ini sering kita sebut jasa. Layanan mungkin tidak nampak di mata publik dan bahkan dari pelanggan. Produk tersebut dapat berupa transfer dana dari rekening tabungan ke rekening giro, transplantasi hati, pengisian kursi kosong di pesawat, atau pendidikan siswa. Terlepas dari apakah produk akhir adalah barang atau jasa, kegiatan produksi yang berlangsung dalam organisasi sering disebut sebagai operasi, atau manajemen operasi. (Heizer \& Render, 2017)

Supply Chain adalah suatu siklus mata rantai yang meliputi seluruh pihak dan fungsi serta proses yang terlibat di dalamnya baik secara langsung maupun tidak langsung dalam memenuhi permintaan konsumen, dari mulai pemasok, produsen, jasa transportasi, distribusi, pergudangan, keuangan, bahkan sampai kepada pengguna akhir itu sendiri. (Chopra, 2020)

Milk Run adalah suatu strategi di mana siklus perjalanan pengantaran barang dari titik awal hingga titik akhir Kembali lagi ke titik awal dengan mengoptimalkan sejumlah strategi pengantaran dan penjemputan produk di dalam rute tersebut. Di mana dalam perkembangannya, strategi tersebut selalu mengalami pembaharuan karena adanya masalah masalah baru dalam pengantaran atau distribusi barang, seperti misalnya menggabungkan beberapa lot kecil pengantaran ke dalam satu lot besar pengantaran, ataupun memecah lot besar ke dalam beberapa kombinasi lot kecil guna mengoptimalkan dari segi biaya maupun waktu, maupun memutar arah perjalanan dari searah jarum jam menjadi berlawanan arah jarum jam. Hal tersebut telah diteliti oleh Chopra (2020), dan Arvidsson (2013) serta Meusel (1995). 
Cold Chain atau yang lazim disebut sebagai rantai dingin adalah rantai pasokan yang dikontrol suhu. Di mana untaian mata rantai dingin yang tidak terputus merupakan rangkaian aktivitas produksi, penyimpanan, dan distribusi berpendingin yang tidak terputus, bersama dengan peralatan dan logistik terkait, yang menjaga kualitas melalui kisaran suhu rendah yang diinginkan. Sehingga dipergunakan untuk melestarikan dan memperpanjang dan memastikan umur simpan produk, seperti produk pertanian segar, makanan laut, makanan beku, film fotografi, bahan kimia, dan produk farmasi. Produk seperti itu, selama pengangkutan dan ketika dalam penyimpanan sementara, lazimnya disebut kargo dingin. Tidak seperti produk lain, barang rantai dingin mudah rusak dan selalu dalam perjalanan menuju penggunaan akhir atau tujuan, bahkan ketika disimpan sementara di toko dingin dan karenanya sering disebut sebagai "kargo" selama seluruh siklus logistiknya. Penyimpanan dingin yang memadai, menjadi sangat penting untuk mencegah kehilangan makanan baik secara kuantitatif maupun kualitatif, di mana hal tersebut senada dengan pendapat dari WHO (2020), dan Kohli (2020), serta Smyrlis (2020) dan juga FAO (2019).

\section{Metode Penelitian}

Metode penelitian menggunakan pendekatan riset operasional matematis, di mana, uji analisa kuantitatif akan berfokus kepada pendekatan manajemen operasional dengan memperhatikan variabel-variabel: Jarak tempuh keseluruhan rute ; Kecepatan lalu lintas ; Jumlah titik singgah yang harus dilayani dalam rute milk run; Lamanya waktu tempuh perjalanan; Kapasitas kendaraan terhadap waktu tempuh dan jumlah layanan singgah; Batasan kapasitas kendaraan yang diperbolehkan dalam rute tertentu.

Adapun kerangka kerja dari operasionalisasi variabel adalah sebagai berikut:

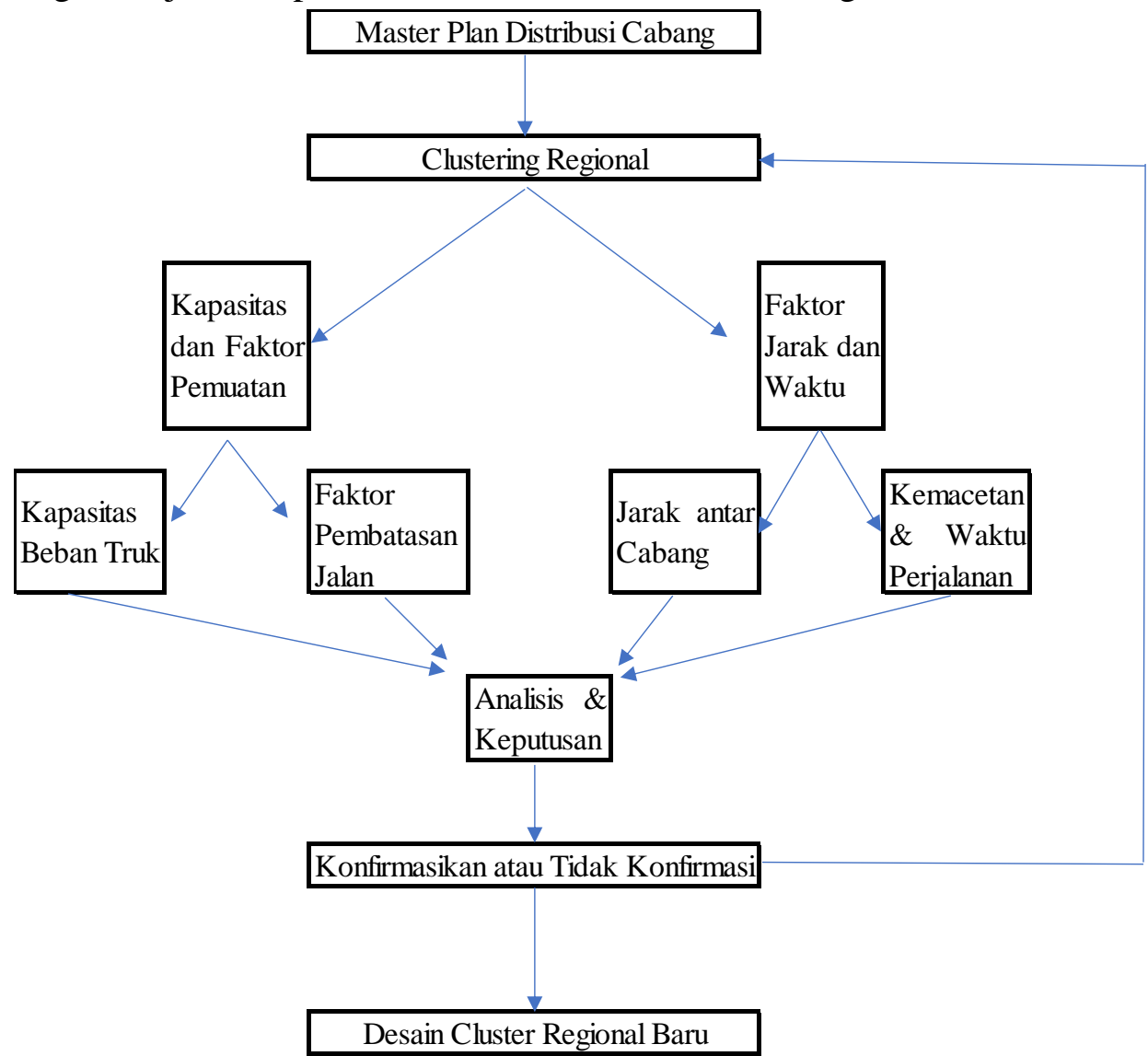

Gambar 1. Kerangka kerja design transportasi rantai dingin logistik 


\section{Pembahasan}

Faktor muatan rute milk run versus masalah pembatasan jalan, biasanya, dalam kondisi, di mana bisnis yang tumbuh cepat memiliki pertumbuhan yang berdampak ke rute milk run, maka manajer akan membagi rute mereka menjadi dua sub rute yang dapat dilayani oleh dua truk yang berbeda, atau dalam beberapa kasus menggunakan truk yang sama tetapi melayani di hari yang berbeda (yang seharusnya memperhitungkan kapasitas pengiriman dapat bertahan selama dua hari konsumsi). Akan tetapi tidak semua jalan memiliki kebijakan yang sama, bahkan dalam hal ini, toko yang berlokasi di kabupaten yang sama, tidak memiliki kebijakan kapasitas jalan yang sama. Misalnya, kargo truk kulkas 26 kaki, dapat menangani hingga lima toko jika perusahaan ingin membagi sembilan toko menjadi dua rute milk run.

Masalah lain muncul di cabang MJG yang terletak di area blok perumahan yang hanya memungkinkan truk kulkas maksimum 20 kaki untuk memasuki area itu. Sebaliknya, toko EMB dan BIN yang berlokasi di wilayah distrik yang sama, bisa melewati truk kulkas setinggi 26 kaki. Kondisi ini membuat rute pengangkutan tidak bisa dilayani oleh truk yang sama, bahkan toko-toko tersebut berada di lokasi area yang sama yang saling berdekatan. Untuk mengatasi masalah ini, manajer transportasi, harus mendesain ulang strategi mereka dan membagi beberapa area yang sama, menjadi area lain yang dapat dilayani oleh armada ukuran yang sama atau lebih kecil.

Adapun contoh perhitungan terdapat di bawah ini:

Tabel 1 : Hasil sebelum dibagi bagi dua ke dalam dua rute milk run

\begin{tabular}{|c|c|c|c|c|c|c|c|c|c|}
\hline No & Toko & Kota & $\begin{array}{c}\text { Gudang } \\
\text { DC }\end{array}$ & $\begin{array}{c}\text { Biaya/ } \\
\text { KM }\end{array}$ & $\begin{array}{l}\text { Jarak } \\
\text { (KM) }\end{array}$ & $\begin{array}{c}\text { Biaya } \\
\text { kirim } \\
\text { langsung }\end{array}$ & $\begin{array}{l}\text { Milk } \\
\text { Run } \\
(\mathbf{K M})\end{array}$ & $\begin{array}{c}\text { Biaya } \\
\text { milk } \\
\text { run / } \\
\text { wilayah }\end{array}$ & Waktu \\
\hline 1 & MJG & $\begin{array}{l}\text { Tangerang } \\
\text { Selatan }\end{array}$ & $\begin{array}{l}\text { DC } \\
\text { Jakarta }\end{array}$ & 930.0 & 50 & 93000 & \multirow{9}{*}{119.6} & \multirow{9}{*}{111228} & \multirow{9}{*}{$\begin{array}{l}4 \text { jam } \\
15 \\
\text { menit }\end{array}$} \\
\hline 2 & BSD & $\begin{array}{l}\text { Tangerang } \\
\text { Selatan }\end{array}$ & $\begin{array}{l}\text { DC } \\
\text { Jakarta }\end{array}$ & 930.0 & 57 & 106020 & & & \\
\hline 3 & EBC & $\begin{array}{l}\text { Tangerang } \\
\text { Selatan }\end{array}$ & $\begin{array}{l}\text { DC } \\
\text { Jakarta }\end{array}$ & 930.0 & 53 & 98580 & & & \\
\hline 4 & SUN & $\begin{array}{l}\text { Tangerang } \\
\text { Selatan }\end{array}$ & $\begin{array}{l}\text { DC } \\
\text { Jakarta }\end{array}$ & 930.0 & 50 & 93000 & & & \\
\hline 5 & EMB & $\begin{array}{l}\text { Tangerang } \\
\text { Selatan }\end{array}$ & $\begin{array}{l}\text { DC } \\
\text { Jakarta }\end{array}$ & 930.0 & 45 & 83700 & & & \\
\hline 6 & BIN & $\begin{array}{l}\text { Tangerang } \\
\text { Selatan }\end{array}$ & $\begin{array}{l}\text { DC } \\
\text { Jakarta }\end{array}$ & 930.0 & 41 & 76260 & & & \\
\hline 7 & PCA & $\begin{array}{l}\text { Tangerang } \\
\text { Selatan }\end{array}$ & $\begin{array}{l}\text { DC } \\
\text { Jakarta }\end{array}$ & 930.0 & 38 & 70680 & & & \\
\hline 8 & SGA & $\begin{array}{l}\text { Tangerang } \\
\text { Selatan }\end{array}$ & $\begin{array}{l}\text { DC } \\
\text { Jakarta }\end{array}$ & 930.0 & 52 & 96720 & & & \\
\hline 9 & CTS & $\begin{array}{l}\text { Tangerang } \\
\text { Selatan }\end{array}$ & $\begin{array}{l}\text { DC } \\
\text { Jakarta }\end{array}$ & 930.0 & 40 & 74400 & & & \\
\hline
\end{tabular}

Sumber : Data primer wilayah BSD, Bintaro dan Ciputat sebelum diolah 2020 
Tabel 2 : Hasil sesudah dibagi bagi dua ke dalam dua rute milk run

\begin{tabular}{|c|c|c|c|c|c|c|c|c|c|}
\hline No & Toko & Kota & $\begin{array}{c}\text { Gudang } \\
\text { DC }\end{array}$ & $\begin{array}{l}\text { Biaya } \\
\text { / KM }\end{array}$ & $\begin{array}{l}\text { Jarak } \\
(\mathrm{KM})\end{array}$ & $\begin{array}{c}\text { Biaya } \\
\text { kirim } \\
\text { langsung }\end{array}$ & $\begin{array}{l}\text { Milk } \\
\text { Run } \\
\text { (KM) }\end{array}$ & $\begin{array}{c}\text { Biaya } \\
\text { milk } \\
\text { run / } \\
\text { wilayah }\end{array}$ & Waktu \\
\hline 1 & MJG & $\begin{array}{l}\text { Tangerang } \\
\text { Selatan }\end{array}$ & $\begin{array}{l}\text { DC } \\
\text { Jakarta }\end{array}$ & 930.0 & 50 & 93000 & \multirow{4}{*}{114} & \multirow{4}{*}{106020} & \multirow{4}{*}{$\begin{array}{l}2 \text { jam } \\
49 \\
\text { menit }\end{array}$} \\
\hline 2 & BSD & $\begin{array}{l}\text { Tangerang } \\
\text { Selatan }\end{array}$ & $\begin{array}{l}\text { DC } \\
\text { Jakarta }\end{array}$ & 930.0 & 57 & 106020 & & & \\
\hline 3 & EBC & $\begin{array}{l}\text { Tangerang } \\
\text { Selatan }\end{array}$ & $\begin{array}{l}\text { DC } \\
\text { Jakarta }\end{array}$ & 930.0 & 53 & 98580 & & & \\
\hline 4 & SUN & $\begin{array}{l}\text { Tangerang } \\
\text { Selatan }\end{array}$ & $\begin{array}{l}\text { DC } \\
\text { Jakarta }\end{array}$ & 930.0 & 50 & 93000 & & & \\
\hline 1 & CTS & $\begin{array}{l}\text { Tangerang } \\
\text { Selatan }\end{array}$ & $\begin{array}{l}\text { DC } \\
\text { Jakarta }\end{array}$ & 930.0 & 40 & 74400 & \multirow{5}{*}{110} & \multirow{5}{*}{102300} & \multirow{5}{*}{$\begin{array}{l}3 \text { jam } \\
15 \\
\text { menit }\end{array}$} \\
\hline 2 & PCA & $\begin{array}{l}\text { Tangerang } \\
\text { Selatan }\end{array}$ & $\begin{array}{l}\text { DC } \\
\text { Jakarta }\end{array}$ & 930.0 & 38 & 70680 & & & \\
\hline 3 & SGA & $\begin{array}{l}\text { Tangerang } \\
\text { Selatan }\end{array}$ & $\begin{array}{l}\text { DC } \\
\text { Jakarta }\end{array}$ & 930.0 & 52 & 96720 & & & \\
\hline 4 & BIN & $\begin{array}{l}\text { Tangerang } \\
\text { Selatan }\end{array}$ & $\begin{array}{l}\text { DC } \\
\text { Jakarta }\end{array}$ & 930.0 & 41 & 76260 & & & \\
\hline 5 & EMB & $\begin{array}{l}\text { Tangerang } \\
\text { Selatan }\end{array}$ & $\begin{array}{l}\text { DC } \\
\text { Jakarta }\end{array}$ & 930.0 & 45 & 83700 & & & \\
\hline
\end{tabular}

Sumber : Data primer wilayah BSD dan Bintaro serta Ciputat setelah diolah 2020

Dari data diatas dapat diketahui bahwa walaupun biaya rute milk run menjadi membengkak karena dari satu armada cargo besar dipecah menjadi dua armada cargo kecil, namun dari sisi kecepatan pelayanan dan distribusi menjadi lebih cepat, sehingga kebutuhan klien dapat terlayani secara cepat. Pengelompokan di atas selain pertimbangan pengelompokan area dan lokasi yang sama, ada beberapa ruas jalan yang kebetulan masuk ke dalam kompleks permukiman memiliki batas ketinggian armada logistik, dan memiliki batasan beban jalan, sehingga harus dikelompokan ulang lokasi-lokasi restoran cepat saji mana saja yang berada di area pemukiman dan memiliki batasan beban jalan dan batas ketinggian portal.

Sementara untuk kondisi lalu lintas dan faktor rute dapat dianalisa dengan menggunakan rute milk run biasanya mengasumsikan bahwa jarak tempuh akan lebih baik jika rute sedekat mungkin, kadang-kadang bukan faktor ideal dalam menghitung efisiensi bahan bakar vs waktu. Misalnya, dengan kondisi sebagai berikut:

a) Di Jakarta dan daerah penyangga, yang jalur lalu lintas di kota ini secepat hanya rata-rata $22 \mathrm{~km} /$ jam, konsumsi bahan bakar paling baik hanya 1-liter untuk $10 \mathrm{~km}$ (pada kapasitas muatan penuh di atas truk).

b) Tetapi jika lalu lintas dapat meningkat sekitar 50 hingga $80 \mathrm{~km} /$ jam dengan situasi awal dan pergi minimum, maka konsumsi bahan bakar dapat dikurangi menjadi 1-liter untuk memasok $15 \mathrm{~km}$ pada kapasitas penuh.

c) Maka itu tidak memadai jika manajer hanya bergantung pada seberapa jauh jarak rute harus dijalankan, ia harus dapat menghitung kecepatan dan kondisi lalu lintas, juga rute terbaik yang bisa ia terima. Perhitungan kami menggunakan biaya per $\mathrm{km}$ berdasarkan ini: Harga bahan bakar untuk diesel (Indonesia masih menggunakan standar Euro 2) dengan harga 
9300 rupiah. Jika konsumsi bahan bakar 1 liter per $10 \mathrm{~km}$, maka seharusnya sekitar 930 rupiah per km namun ketika konsumsi berkurang menjadi 1 liter per $15 \mathrm{~km}$, maka itu akan membantu mengurangi biaya transportasi menjadi 620 rupiah per $\mathrm{km}$.

Saat ini yang perlu diperhatikan, mengapa manajer masih menggunakan rencana biaya pada 930 rupiah per kilometer, adalah karena kemacetan lalu lintas tidak dapat diprediksi, dan berbahaya bagi manajer untuk membuat rencana anggaran jika didasarkan pada kondisi lalu lintas yang tidak dapat diprediksi, sehingga perhitungan ini harus menggunakan skenario terburuk, tapi perjalanan kami menggunakan rute optimal berdasarkan kondisi lalu lintas harian yang ditampilkan di google maps.

Namun untuk rutinitas sehari-hari, semua pengemudi harus membandingkan rencana rute yang telah dirancang menggunakan peta google dengan aplikasi waze mereka di smartphone mereka. Contoh perhitungan pada tabel di bawah untuk Kondisi Lalu Lintas dan Faktor Rute dengan memasukkan searah jarum jam menjadi berlawanan arah jarum jam:

Tabel 3. Kondisi Lalu Lintas dan Faktor Rute dengan searah arah jarum jam

\begin{tabular}{|c|c|c|c|c|c|c|c|c|c|}
\hline No & Toko & Kota & $\begin{array}{c}\text { Gudang } \\
\text { DC }\end{array}$ & $\begin{array}{l}\text { Biaya / } \\
\text { KM }\end{array}$ & $\begin{array}{l}\text { Jarak } \\
(\mathbf{K M})\end{array}$ & $\begin{array}{c}\text { Biaya } \\
\text { kirim } \\
\text { langsung }\end{array}$ & $\begin{array}{c}\text { Milk } \\
\text { Run } \\
\text { (KM) }\end{array}$ & $\begin{array}{c}\text { Biaya } \\
\text { milk } \\
\text { run / } \\
\text { wilayah }\end{array}$ & Waktu \\
\hline 1 & LNI & $\begin{array}{l}\text { Tangerang } \\
\text { Kota }\end{array}$ & $\begin{array}{l}\text { DC } \\
\text { Jakarta }\end{array}$ & 930.0 & 37 & 68820 & \multirow{4}{*}{107} & \multirow{4}{*}{99510} & \multirow{4}{*}{$\begin{array}{l}3 \text { jam } \\
11 \\
\text { menit }\end{array}$} \\
\hline 2 & KRM & $\begin{array}{l}\text { Tangerang } \\
\text { Kota }\end{array}$ & $\begin{array}{l}\text { DC } \\
\text { Jakarta }\end{array}$ & 930.0 & 35 & 65100 & & & \\
\hline 3 & GRT & $\begin{array}{l}\text { Tangerang } \\
\text { Selatan }\end{array}$ & $\begin{array}{l}\text { DC } \\
\text { Jakarta }\end{array}$ & 930.0 & 44 & 81840 & & & \\
\hline 4 & ASU & $\begin{array}{l}\text { Tangerang } \\
\text { Selatan }\end{array}$ & $\begin{array}{l}\text { DC } \\
\text { Jakarta }\end{array}$ & 930.0 & 45 & 83700 & & & \\
\hline
\end{tabular}

Sumber: Data primer wilayah Tangerang Kota, Alam Sutera dan Karang Tengah sebelum diolah 2020

Jika kita mengasumsikan kecepatan sekitar $50 \mathrm{~km} /$ jam dan biaya berkurang menjadi 620 rupiah per km, biaya dapat berkurang dari 99.510 rupiah menjadi 65.100 rupiah dan dari 3 jam 11 menit menjadi 3 jam 2 menit, hanya dengan mengubah arah rute searah jarum jam, menjadi berlawanan arah jarum jam.

Tabel 4. Kondisi arah rute dengan mengacu arah jarum jam, menjadi berlawanan arah jarum jam

\begin{tabular}{|c|c|c|l|r|r|r|r|r|r|}
\hline No & Toko & Kota & $\begin{array}{l}\text { Gudang } \\
\text { DC }\end{array}$ & $\begin{array}{c}\text { Biaya / } \\
\text { KM }\end{array}$ & $\begin{array}{c}\text { Jarak } \\
\text { (KM) }\end{array}$ & $\begin{array}{c}\text { Biaya } \\
\text { kirim } \\
\text { langsung }\end{array}$ & $\begin{array}{c}\text { Milk } \\
\text { Run } \\
\text { (KM) }\end{array}$ & $\begin{array}{c}\text { Biaya } \\
\text { milk } \\
\text { run / } \\
\text { wilayah }\end{array}$ & Waktu \\
\cline { 1 - 5 } 1 & ASU & $\begin{array}{l}\text { Tangerang } \\
\text { Selatan }\end{array}$ & $\begin{array}{l}\text { DC } \\
\text { Jakarta }\end{array}$ & 620.0 & 45 & 55800.0 & \multirow{2}{*}{105} & 65100 & $\begin{array}{l}3 \\
2 \\
\text { menit }\end{array}$ \\
\hline
\end{tabular}


Alexander Batara Marpaung, Elia Oey, Rianto Nurcahyo

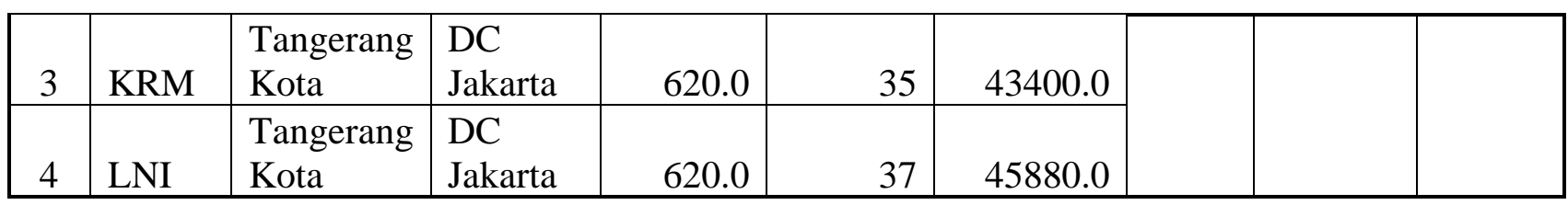

Sumber : Data primer wilayah Tangerang Kota, Karang Tengah dan Alam Sutera setelah diolah 2020

Namun demikian, manajer dalam merencanakan rencana budget, harus tetap mempertimbangkan skenario terburuk, dikarenakan faktor-faktor tidak terduga yang umumnya terjadi dalam wilayah Jabodetabek, seperti kecelakaan lalu lintas, demonstrasi dan penutupan jalan, hingga faktor gangguan lampu lalu lintas maupun cuaca seperti banjir dan lain sebagainya. Dengan demikian, manajer tetap lebih baik menggunakan budget sebesar 930 rupiah per km, sehingga membuat rencana pengeluaran biaya transport sebesar 97.650 rupiah untuk rute milk run ini.

Tabel 5. Anggaran berdasarkan pengeluaran untuk Biaya Transportasi Pada Milk Run

\begin{tabular}{|c|c|c|c|c|c|c|c|c|c|}
\hline No & Toko & Kota & $\begin{array}{c}\text { Gudang } \\
\text { DC }\end{array}$ & $\begin{array}{c}\text { Biaya/ } \\
\text { KM }\end{array}$ & $\begin{array}{l}\text { Jarak } \\
\text { (KM) }\end{array}$ & $\begin{array}{c}\text { Biaya } \\
\text { kirim } \\
\text { langsung }\end{array}$ & $\begin{array}{c}\text { Milk } \\
\text { Run } \\
\text { (KM) }\end{array}$ & $\begin{array}{c}\text { Biaya } \\
\text { milk } \\
\text { run / } \\
\text { wilayah }\end{array}$ & Waktu \\
\hline 1 & ASU & $\begin{array}{l}\text { Tangerang } \\
\text { Selatan }\end{array}$ & $\begin{array}{l}\text { DC } \\
\text { Jakarta }\end{array}$ & 930.0 & 45 & 83700.0 & \multirow{4}{*}{105} & \multirow{4}{*}{97650} & \multirow{4}{*}{$\begin{array}{l}3 \text { jam } \\
2 \\
\text { menit }\end{array}$} \\
\hline 2 & GRT & $\begin{array}{l}\text { Tangerang } \\
\text { Selatan }\end{array}$ & $\begin{array}{l}\text { DC } \\
\text { Jakarta }\end{array}$ & 930.0 & 44 & 81840.0 & & & \\
\hline 3 & KRM & $\begin{array}{l}\text { Tangerang } \\
\text { Kota }\end{array}$ & $\begin{array}{l}\text { DC } \\
\text { Jakarta }\end{array}$ & 930.0 & 35 & 65100.0 & & & \\
\hline 4 & LNI & $\begin{array}{l}\text { Tangerang } \\
\text { Kota }\end{array}$ & $\begin{array}{l}\text { DC } \\
\text { Jakarta }\end{array}$ & 930.0 & 37 & 68820.0 & & & \\
\hline
\end{tabular}

Sumber: Data primer wilayah Alam Sutera, Karang Tengah dan Tangerang Kota sesudah diolah 2020

Batasan faktor muatan, dan waktu rute serta cara menangani jarak tempuh yang jauh merupakah saat untuk merancang rute jalur milk run, akan lebih mudah jika jaraknya dekat, bukan jarak jauh, misalnya lebih dari $50 \mathrm{~km}$ dari DC Warehouse. Menambahkan DC Warehouse baru terkadang tidak tiba-tiba menghilangkan masalah. Dalam hal ini, Gudang DC Jakarta harus melayani dua toko di Lampung (Pulau Sumatera), dua toko di Palembang (Pulau Sumatra) dan satu di Pulau Batam. Alasan di balik fakta bahwa DC Warehouse Medan yang berlokasi di Sumatera Utara, memiliki keterbatasan untuk melayani ke wilayah jauh selatan pulau Sumatera, dan pulau Batam yang dekat DC Warehouse Medan tidak dapat dilayani oleh gudang itu karena kapasitas gudang kecil dan sebagian besar pemasok makanan berlokasi di Jakarta atau harus mengirim melalui pelabuhan Tanjung Priok yang berlokasi di Jakarta. 
Tabel 6. Biaya dan waktu yang ditempuh (Km) untuk Milk Run Sumatra dan Banten

\begin{tabular}{|c|c|c|c|c|c|c|c|c|c|}
\hline No & Toko & Kota & $\begin{array}{c}\text { Gudang } \\
\text { DC }\end{array}$ & $\begin{array}{l}\text { Biaya } \\
\text { / KM }\end{array}$ & $\begin{array}{l}\text { Jarak } \\
\text { (KM) }\end{array}$ & $\begin{array}{c}\text { Biaya } \\
\text { kirim } \\
\text { langsung }\end{array}$ & $\begin{array}{l}\text { Milk } \\
\text { Run } \\
\text { (KM) }\end{array}$ & $\begin{array}{c}\text { Biaya } \\
\text { milk } \\
\text { run / } \\
\text { wilayah }\end{array}$ & Waktu \\
\hline 1 & BHS & Batam & $\begin{array}{l}\text { DC } \\
\text { Jakarta }\end{array}$ & 8665.5 & 1154 & 10000000 & 0 & 0 & $\begin{array}{l}64 \text { jam } \\
(2 \text { hari } \\
16 \text { jam })\end{array}$ \\
\hline 2 & SKT & Palembang & $\begin{array}{l}\text { DC } \\
\text { Jakarta }\end{array}$ & 930.0 & 622 & 1156920 & \multirow{5}{*}{1256} & \multirow{5}{*}{1168080} & \multirow{5}{*}{$\begin{array}{l}29 \text { jam } \\
\text { (1 hari } 5 \\
\text { jam) }\end{array}$} \\
\hline 3 & RSP & Palembang & $\begin{array}{l}\text { DC } \\
\text { Jakarta }\end{array}$ & 930.0 & 620 & 1153200 & & & \\
\hline 4 & KNL & Lampung & $\begin{array}{l}\text { DC } \\
\text { Jakarta }\end{array}$ & 930.0 & 253 & 470580 & & & \\
\hline 5 & PTK & Lampung & $\begin{array}{l}\text { DC } \\
\text { Jakarta }\end{array}$ & 930.0 & 245 & 455700 & & & \\
\hline 6 & SGC & Banten & $\begin{array}{l}\text { DC } \\
\text { Jakarta }\end{array}$ & 930.0 & 98 & 182280 & & & \\
\hline
\end{tabular}

Sumber : Data primer wilayah Sumatra dan Banten sebelum diolah 2020

Untuk Pulau Batam, biaya per km berubah karena perusahaan menggunakan kapal kargo daripada pengiriman truk normal, sehingga pengiriman dapat menggunakan kargo kontainer hingga 45 kaki yang dapat bertahan selama 10 hari konsumsi di toko-toko. Ini akan membuat biaya transportasi dan pemanfaatan lebih optimal daripada menggunakan kargo yang lebih kecil yang memiliki biaya pengiriman hampir sama pada kisaran 10 juta rupiah. Namun untuk menyelesaikan masalah menggunakan metode ini tidak seakurat pemikiran. Sebagai komplikasi muncul dalam menjalankan rute milk run, yang membutuhkan waktu lebih dari 1 hari. Toko SGC yang berlokasi di Banten (Jawa Barat), mengambil tempat penyimpanan lain di dalam truk kargo untuk rute Palembang dan Lampung, yang membuat inventaris akan bertahan sebelum akhir 2 hari di toko-toko dan untuk menghilangkan masalah itu, manajer harus menghapus perjalanan toko SGC, dan menggabungkannya ke dalam rute milk run lainnya, untuk memanfaatkan pada tingkat layanan yang optimal. Oleh sebab itu manajer, menggabungkan toko SGC dengan toko BCC yang mengambil dari rute sebagai berikut :

Tabel 7 : Rute Milk Run Cabang BCC yang sebelumnya masuk ke dalam rute TangSel

\begin{tabular}{|c|c|c|c|c|c|c|c|c|c|}
\hline No & Toko & Kota & $\begin{array}{c}\text { Gudang } \\
\text { DC }\end{array}$ & $\begin{array}{l}\text { Biaya } \\
\text { / KM }\end{array}$ & $\begin{array}{r}\text { Jarak } \\
(\mathbf{K M})\end{array}$ & $\begin{array}{c}\text { Biaya } \\
\text { kirim } \\
\text { langsu } \\
\text { ng }\end{array}$ & $\begin{array}{c}\text { Milk } \\
\text { Run } \\
\text { (KM) }\end{array}$ & $\begin{array}{c}\text { Biaya } \\
\text { milk run } \\
\text { / } \\
\text { wilayah }\end{array}$ & Waktu \\
\hline 1 & $\mathrm{BCC}$ & $\begin{array}{l}\text { Tangerang } \\
\text { Kabupaten }\end{array}$ & $\begin{array}{l}\text { DC } \\
\text { Jakarta }\end{array}$ & 930.0 & 57 & 106020 & \multirow{3}{*}{127} & \multirow{3}{*}{118110} & \multirow{3}{*}{$\begin{array}{l}3 \text { jam } \\
15 \\
\text { menit }\end{array}$} \\
\hline 2 & LPV & $\begin{array}{l}\text { Tangerang } \\
\text { Kabupaten }\end{array}$ & $\begin{array}{l}\text { DC } \\
\text { Jakarta }\end{array}$ & 930.0 & 46 & 85560 & & & \\
\hline 3 & LKA & $\begin{array}{l}\text { Tangerang } \\
\text { Kabupaten }\end{array}$ & $\begin{array}{l}\text { DC } \\
\text { Jakarta }\end{array}$ & 930.0 & 44 & 81840 & & & \\
\hline
\end{tabular}


INOBIS: Jurnal Inovasi Bisnis dan Manajemen Indonesia

Volume 05, Nomor 01, Desember 2021

Alexander Batara Marpaung, Elia Oey, Rianto Nurcahyo

\begin{tabular}{|r|l|l|l|r|r|r|} 
& & Tangerang & DC & & & \\
4 & SDC & Kabupaten & Jakarta & 930.0 & 48 & 89280 \\
\hline & & $\begin{array}{l}\text { Tangerang } \\
\text { 5 }\end{array}$ & DC & & & \\
Kabupaten & Jakarta & 930.0 & 44 & 81840 \\
\hline
\end{tabular}

Sumber: Data primer wilayah Tangerang Selatan sebelum diolah 2020

Tabel 8 : Rute baru cabang SGC dan cabang BCC

\begin{tabular}{|c|c|c|c|c|c|c|c|c|c|}
\hline No & Toko & Kota & $\begin{array}{c}\text { Gudang } \\
\text { DC }\end{array}$ & $\begin{array}{l}\text { Biaya } \\
\text { / KM }\end{array}$ & $\begin{array}{l}\text { Jarak } \\
(\mathrm{KM})\end{array}$ & $\begin{array}{c}\text { Biaya } \\
\text { kirim } \\
\text { langsung }\end{array}$ & $\begin{array}{c}\text { Milk } \\
\text { Run } \\
(\mathbf{K M})\end{array}$ & $\begin{array}{c}\text { Biaya } \\
\text { milk run / } \\
\text { wilayah }\end{array}$ & Waktu \\
\hline 1 & SGC & Banten & $\begin{array}{l}\text { DC } \\
\text { Jakarta }\end{array}$ & 930.0 & 98 & 182280 & \multirow{2}{*}{205} & \multirow{2}{*}{190650} & \multirow{2}{*}{$\begin{array}{l}4 \text { jam } \\
39 \\
\text { menit }\end{array}$} \\
\hline 2 & $\mathrm{BCC}$ & $\begin{array}{l}\text { Tangerang } \\
\text { Kabupaten }\end{array}$ & $\begin{array}{l}\text { DC } \\
\text { Jakarta }\end{array}$ & 930.0 & 57 & 106020 & & & \\
\hline
\end{tabular}

Sumber : Data primer wilayah Banten dan Tangerang sesudah diolah 2020

Oleh karena itu, manajemen untuk rute milk run sebelumnya di mana toko BCC keluar, menjadi seperti berikut ini:j

Tabel 9 : Perubahan untuk Rute Mik Run Wilayah TangSel

\begin{tabular}{|c|c|c|c|c|c|c|c|c|c|}
\hline No & Toko & Kota & $\begin{array}{c}\text { Gudang } \\
\text { DC }\end{array}$ & $\begin{array}{c}\text { Biaya / } \\
\text { KM }\end{array}$ & $\begin{array}{l}\text { Jarak } \\
\text { (KM) }\end{array}$ & $\begin{array}{c}\text { Biaya } \\
\text { kirim } \\
\text { langsung }\end{array}$ & $\begin{array}{c}\text { Milk } \\
\text { Run } \\
(\mathbf{K M})\end{array}$ & $\begin{array}{c}\text { Biaya } \\
\text { milk } \\
\text { run / } \\
\text { wilayah }\end{array}$ & Waktu \\
\hline 1 & LKA & $\begin{array}{l}\text { Tangerang } \\
\text { Kabupaten }\end{array}$ & $\begin{array}{l}\text { DC } \\
\text { Jakarta }\end{array}$ & 930.0 & 44 & 81840 & \multirow{4}{*}{104} & \multirow{4}{*}{96720} & \multirow{4}{*}{$\begin{array}{l}2 \text { jam } \\
35 \\
\text { menit }\end{array}$} \\
\hline 2 & LPV & $\begin{array}{l}\text { Tangerang } \\
\text { Kabupaten }\end{array}$ & $\begin{array}{l}\text { DC } \\
\text { Jakarta }\end{array}$ & 930.0 & 46 & 85560 & & & \\
\hline 3 & SDC & $\begin{array}{l}\text { Tangerang } \\
\text { Kabupaten }\end{array}$ & $\begin{array}{l}\text { DC } \\
\text { Jakarta }\end{array}$ & 930.0 & 48 & 89280 & & & \\
\hline 4 & GDS & $\begin{array}{l}\text { Tangerang } \\
\text { Kabupaten }\end{array}$ & $\begin{array}{l}\text { DC } \\
\text { Jakarta }\end{array}$ & 930.0 & 44 & 81840 & & & \\
\hline
\end{tabular}

Sumber : Data primer wilayah Tangerang Selatan sesudah diolah 2020

Sekarang persediaan dengan hanya 4 toko untuk dilayani, dapat bertahan selama 2 hari sebelum perlu diisi ulang. Situasi serupa terjadi dengan rute milk run untuk Lampung dan Palembang yang berubah menjadi berikut ini: 
Tabel 10 : Perubahan rute milk run untuk Lampung dan Palembang

\begin{tabular}{|c|c|c|c|c|c|c|c|c|c|}
\hline No & Toko & Kota & $\begin{array}{c}\text { Gudang } \\
\text { DC }\end{array}$ & $\begin{array}{l}\text { Biaya } \\
\text { / KM }\end{array}$ & $\begin{array}{c}\text { Jarak } \\
(\mathbf{K M})\end{array}$ & $\begin{array}{c}\text { Biaya } \\
\text { kirim } \\
\text { langsung }\end{array}$ & $\begin{array}{c}\text { Milk } \\
\text { Run } \\
\text { (KM) }\end{array}$ & $\begin{array}{c}\text { Biaya } \\
\text { milk run } \\
\text { / wilayah }\end{array}$ & Waktu \\
\hline 1 & SKT & Palembang & $\begin{array}{l}\text { DC } \\
\text { Jakarta }\end{array}$ & 930.0 & 622 & 1156920 & \multirow{4}{*}{1249} & \multirow{4}{*}{1161570} & \multirow{4}{*}{29 jam } \\
\hline 2 & RSP & Palembang & $\begin{array}{l}\text { DC } \\
\text { Jakarta }\end{array}$ & 930.0 & 620 & 1153200 & & & \\
\hline 3 & KNL & Lampung & $\begin{array}{l}\text { DC } \\
\text { Jakarta }\end{array}$ & 930.0 & 253 & 470580 & & & \\
\hline 4 & PTK & Lampung & $\begin{array}{l}\text { DC } \\
\text { Jakarta }\end{array}$ & 930.0 & 245 & 455700 & & & \\
\hline
\end{tabular}

Sumber : Data primer wilayah Sumatera sesudah diolah 2020

\section{Kesimpulan}

Berdasarkan hasil pembahasan dan analisa yang dilakukan didapatkan kesimpulan sebagai berikut: 1) Pengantaran bahan baku makanan cepat saji harus memperhatikan faktor kondisi lalu lintas, sebab di dalam pengiriman barang terkadang rute yang sudah baku harus dimodifikasi berlawanan arah, hal ini bisa terjadi karena situasi lalu lintas di Indonesia terutama kota-kota besar dan kota penyangga yang sangat kompleks sehingga perlu keaktifan manajer dalam memperhatikan rute pengiriman barang. Karena dengan membalikan arah bisa didapat rute perjalanan yang lebih singkat dan juga lebih lancar dari yang tadinya 4 jam lebih menjadi hanya sekitar 3 jam saja, sehingga dengan demikian, biaya transportasi juga bisa lebih ditekan. 2) Penggunaan truk logistik pendingin berukuran besar, tidak selalu dapat menyelesaikan masalah, sebab manager operasional harus juga mempertimbangkan faktor ketepatan waktu, terutama adanya masalah kesegaran makanan yang harus dipertahankan dan segera disajikan, sehingga mau tidak mau harus dapat dipecah ke dalam beberapa klaster pengantaran agar makanan tidak membusuk dalam perjalanan. 3) Pengiriman makanan beku sebagai bahan baku makanan cepat saji, juga perlu memperhatikan kondisi pembatasan jalan, karena di beberapa wilayah, ada larangan kendaraan besar beroperasi keluar masuk kompleks permukiman, sehingga penyusunan kluster pengiriman harus disesuaikan dengan wilayah pengantaran, apakah dengan menggabungkan beberapa wilayah permukiman dalam satu rute pengantaran atau memecahnya ke dalam rute pengantaran yang lain seperti apakah rute pengiriman ke wilayah Melati Mas Tangerang harus digabungkan dengan rute BSD Tangerang atau dipisah dan ternyata dari hasil analisa sebaiknya dipisahkan. 4) Meskipun faktor muatan memegang peranan penting dalam pengiriman, namun masalah daya tahan inventory di lokasi tujuan juga harus diperhatikan, terutama jika ada restoran yang rute pengirimannya tergabung dengan rute jarak jauh antar wilayah provinsi, akan lebih bijaksana jika untuk pengiriman lintas provinsi, maka jatah pengiriman diprioritaskan pada satu wilayah propinsi yang sama, seperti pada kasus pengiriman ke daerah Banten yang harus dipisahkan dari pengiriman ke daerah Palembang ataupun Lampung. Dari kesimpulan ini, para pelaku industri logistik rantai pasok dingin, tidak bisa hanya bersandar pada patokan lama penggunaan kapasitas sebesar-besarnya namun juga harus aktif memetakan rute-rute pengiriman berdasarkan faktor wilayah, faktor kondisi lalu lintas, dan juga faktor persediaan barang. 
Saran bagi peneliti selanjutnya, agar dalam melakukan rencana strategi pengantaran terutama untuk rantai pasok makanan beku, supaya bisa mengembangkan aplikasi software yang sifatnya interaktif dalam mengkalkulasi biaya serta kecepatan pengirman dan dinamis, terhubung ke sistem map dinamis sehingga para pelaku industri dapat lebih focus dalam memasukan data-data tujuan pengiriman dan perencanaan transportasi logistik.

\section{Daftar Pustaka}

Arvidsson, Niklas. (2013). Perjalanan susu ditinjau kembali: Paradoks faktor muatan dengan implikasi ekonomi dan lingkungan untuk transportasi angkutan kota. Jurnal Transportation Research Part A: Policy and Practice, 2013, vol. 51, issue C, 56-62, Elsevier, Europe

Ballou, R.H. (1999). Manajemen Logistik Bisnis. Perencanaan, Pengorganisasian dan Pengendalian Rantai Pasokan. Prentice-Hall, Upper Saddle River, NJ. USA

Chopra, S. (2020). Manajemen Rantai Pasokan: Strategi, Perencanaan, dan Operasi. Edisi ke 7. Pearson Education Limited. USA

Ebben, M.J.R. (2005). Penjadwalan transportasi dinamis di bawah berbagai kendala sumber daya. , European Journal of Operational Research 167 (2005) 320-335, Elsevier, Europe.

FAO. (2019) Bergerak maju dalam kehilangan pangan dan pengurangan limbah. In Brief: The State of Food and Agriculture.

Hall, R.W. (1987). Strategi konsolidasi: inventaris, kendaraan dan terminal. Jurnal Logistik Bisnis 8, 57-73, 1987, Springer, Europe

Hanafi, Yukki, (2020). Pasar Cold Chain Indonesia Tumbuh Cepat, Begini Sudut Pandang Pelaku Logistik, TranslogToday.com.

Heizer, Jay; Render, Barry; Munson, Chuck (2017), Manajemen Operasi, Keberlanjutan dan Manajemen Rantai Pasokan. Edisi ke 12. Pearson Education Limited.

Kohli, Pawanexh. (2020) Perawatan Pasca Panen Buah dan Sayuran: Dasar-dasarnya". CrossTree techno-visors.

Marius, D. \& Lu, M. (2013). Distribusi kontainer cerdas berbasis kualitas dalam jaringan logistik rantai dingin. , hlm.291-297. Jurnal Production Engineering Issue 2-3/2013. Springerprofessional, Jerman.

Meusel, Winrid. (1995): Realisasi konsultan logistik, workstation untuk biaya pengiriman mengendalikan dengan unsur-unsur berbasis pengetahuan. Nuremberg, Univ., Diss. Erlangen, 1995. Frankfurt am Main, Berlin: Lang (Universitas Eropa Seri 5, Ekonomi dan Administrasi Bisnis, 1755). Berlin, Jerman.

Smyrlis, Lou. (2013) Claude Mongeau dari CN mengkhotbahkan 'kolaborasi ekosistem' di hari hari Pelabuhan. Canadian Transportation Logistics.

Xu, X., Lan, H. \& Wang, R. (2010). Identifikasi Poin Kontrol Kritis dari Proses Logistik Rantai Makanan Dingin. , hal.164-168, 2010 International Conference on Logistics Systems and Intelligent Management (ICLSIM), Harbin, China.

Yan, J., Chaudhry, P.E., Chaudhry, S.S. (2003). Sebuah model sistem pendukung keputusan berdasarkan alasan kasus untuk evaluasi logistik pihak ketiga. Sistem Pakar 20 (4), 196-207. Jurnal Expert System, Vol 20, Issue 4, 2003, Willey, USA

Zhang, Y. \& Chen, E. (2014). Sistem pemantauan komprehensif logistik rantai dingin makanan segar. , Jurnal Applied Mechanics and Materials Vols 602-605 (2014) pp 2340-2343, (C) (2014) Trans Tech Publications, Switzerland.

WHO. (2020) Rantai Dingin Vaksinasi. WHO - Panduan Modul Rantai Pasok Dingin Vaksinasi. www.who.int. 